\title{
Concerns about a New Preterm MR Imaging Scoring System
}

W e have read with interest the recently published article by George et al. ${ }^{1}$ Because more centers are performing brain MR imaging in preterm infants before term-equivalent age (TEA), there is indeed a need for a robust and validated scoring system for both documenting injury and help in predicting outcomes. Most of us are using either the score of Woodward et $\mathrm{al}^{2}$ or that of Kidokoro et $\mathrm{al}^{3}$ when assessing the MR imaging performed at TEA, but these scoring systems cannot be used before 36 weeks' postmenstrual age (PMA).

In the article by George et al, ${ }^{1} 83$ preterm infants were studied at a mean PMA of 32 weeks. The scoring system appears easy to use, and 20 MRIs were scored initially by a neurologist with additional training in radiology and subsequently by a radiologist, with overall good interrater reproducibility (intraclass correlation coefficient [ICC], 0.82-0.97) but a low score for cortical gray matter (0.08; ICC, 0.00-0.63). The T2-weighted MR images provided in the supplemental file are of excellent quality. However, we do not agree with the interpretation given to some of them and would like to bring this to the attention of the readers of this journal.

In Fig 2, the image shown is scored as an example of grade 2 white matter injury (WMI). However, the symmetric smoothwalled cysts adjacent to the ventricles are typical of subependymal pseudocysts (SEPs), also referred to as connatal cysts, and they are not in the white matter. They are not uncommon and are sometimes mistaken for cystic periventricular leukomalacia (c-PVL). ${ }^{4,5}$ There are several publications that help us make the distinction between SEPs and c-PVL. ${ }^{6,7}$ First, SEPs are already present at birth and readily visible on cranial sonography; they are below the roof of the lateral ventricles (Fig 1); they are most often seen directly adjacent to the ventricles in the frontal lobe; and the walls of the cysts are smooth and when several are present, they look like a string of beads on a parasagittal view. Distinguishing these cysts from c-PVL or other cysts within the white matter is generally not difficult, and it is very important because the neurodevelopmental outcome of infants with SEPs is almost uniformly within the normal range, as reported by several groups, except when these cysts

http://dx.doi.org/10.3174/ajnr.A5466 are markers for an underlying problem (eg, cytomegalovirus $[\mathrm{CMV}]$ or a metabolic or other rare disorder $)^{6,8-11}$

Another matter of debate is shown in Figs 11, 12, and 14, where germinal matrix hemorrhages are scored as deep gray matter injury. Again, we do not agree with the interpretation given and consider that these images show hemorrhage within the germinal matrix rather than injury being primarily in the central gray nuclei. It is possible that there is injury directly to the gray matter or poor secondary growth, but it is not shown in these images. A similar issue is seen in Fig 7 where low signal is seen on the margin of the ventricle rather than being primarily in the white matter.

In this study of George et $\mathrm{al}^{1}$ the number of infants with a grade 2 cystic WMI score, a deep gray matter injury score, or a linear WM injury score is limited to 1,8 , and 7, respectively. Because these numbers are small, we do not know whether they have much of an impact on the use of their score. We do, however, think that one should be aware of these diagnostic discrepancies. We are especially concerned that SEPs are still being misinterpreted as cystic WMI because only infants with the latter type of injury have an adverse outcome, unless the SEPs are markers for an underlying problem that needs specific investigation that may otherwise not be performed if the cysts are interpreted as c-PVL.

Disclosures: Linda de Vries-UNRELATED: Employment: consultant neonatologist University Medical Center Utrecht; Payment for Lectures Including Service on Speakers Bureaus: neonatal sonography course, Comments: This course runs every year in London, and an honorarium is provided. I am a faculty of IpoKrates and receive an honorarium for lectures*; Royalties, Comments: I am a coauthor of 2 books for which I receive royalties, Atlas of Amplitude Integrated EEGs in the Neonate (ISBN-13:9781841846491) and An Atlas of Neonatal Brain Sonography (ISBN: 978-1-898683-56-8). Frances Cowan-UNRELATED: Employment: part-time perinatal neurologist, Chelsea and Westminster Hospital, London, UK; Payment for Lectures Including Service on Speakers Bureaus, Comments: I speak at an annual neonatal sonography course and receive an honorarium. *Money paid to the institution.

\section{REFERENCES}

1. George JM, Fiori S, Fripp J, et a. Validation of an MRI brain injury and growth scoring system in very preterm infants scanned at 29- to 35-week postmenstrual age. AJNR Am J Neuroradiol 2017;38: 1435-42 CrossRef Medline

2. Woodward LJ, Anderson PJ, Austin NC, et al. Neonatal MRI to predict neurodevelopmental outcomes in preterm infants. $N$ Engl J Med 2006;355:685-94 CrossRef Medline

3. Kidokoro H, Anderson PJ, Doyle LW, et al. Brain injury and altered 
brain growth in preterm infants: predictors and prognosis. Pediatrics 2014;134:e444-53 CrossRef Medline

4. Al Rifai MT, Al Tawil KI. The neurological outcome of isolated PVL and severe IVH in preterm infants: is it fair to compare? Pediatr Neurol 2015;53:427-33 CrossRef Medline

5. Brun N, Robitaille Y, Grignon A, et al. Pyruvate carboxylase deficiency: prenatal onset of ischemia-like brain lesions in two sibs with the acute neonatal form. Am J Med Genet 1999;84:94-101 Medline

6. Rademaker KJ, De Vries LS, Barth PG. Subependymal pseudocysts: ultrasound diagnosis and findings at follow-up. Acta Paediatr 1993; 82:394-99 CrossRef Medline

7. Malinger G, Lev D, Ben Sira L, et al. Congenital periventricular pseudocysts: prenatal sonograph-c appearance and clinical implications. Ultrasound Obstet Gynecol 2002;20:447-51 CrossRef Medline

8. Cevey-Macherel M, Forcada Guex M, Bickle Graz M, et al. Neurodevelopment outcome of newborns with cerebral subependymal pseudocysts at $\mathbf{1 8}$ and $\mathbf{4 6}$ months: a prospective study. Arch Dis Child 2013;98:497-502 CrossRef Medline
9. Larcos G, Gruenewald SM, Lui K. Neonatal subependymal cysts detected by sonography: prevalence, sonographic findings, and clinical significance. AJR Am J Roentgenol 1994;162:953-56 CrossRef Medline

10. Ramenghi LA, Domizio S, Quartulli L, et al. Prenatal pseudocysts of the germinal matrix in preterm infants. J Clin Ultrasound 1997;25: 169-73 Medline

11. Leijser LM, de Vries LS, Rutherford MA, et al. Cranial ultrasound in metabolic disorders presenting in the neonatal period: characteristic features and comparison with MR imaging. AJNR Am J Neuroradiol 2007;28:1223-31 CrossRef Medline

(D)L.S. de Vries Department of Neonatology University Medical Center, Utrecht University Utrecht, the Netherlands

DF.M. Cowan

Neonatal Department Chelsea and Westminster Hospital Imperial College London, UK
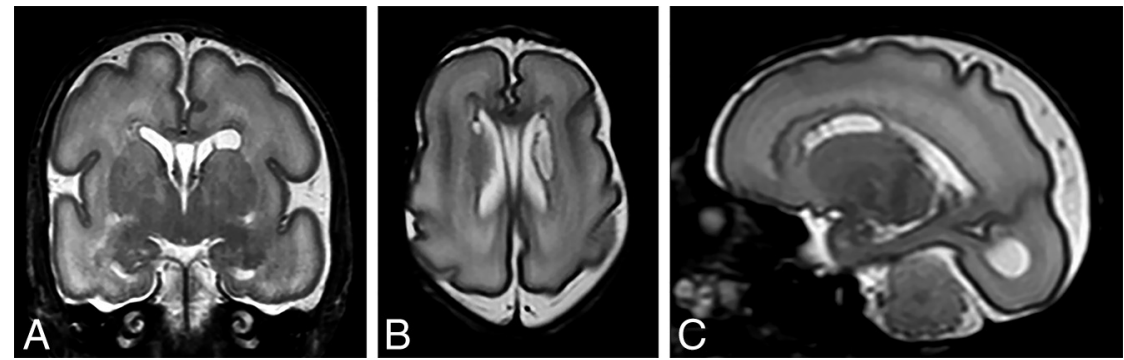

FIG 1. T2-weighted coronal $(A)$, axial $(B)$, and parasagittal $(C)$ MR images showing smooth-walled subependymal cysts, mainly sited directly adjacent to the anterior ventricular margins. 